\title{
Improvement in Renal Function in Participants in the First UK National Health Service (NHS) EndoBarrier Service for Uncontrolled Diabesity
}

Robert EJ Ryder ${ }^{1}$, Piya Sen Gupta ${ }^{1,2}$, Mahi Yadagiri ${ }^{1}$, Susan P Irwin ${ }^{1}$, Wyn Burbridge ${ }^{1}$, Tahira Bashir ${ }^{1}$, Rachael A Allden ${ }^{1}$, Melanie Wyres ${ }^{1}$, Melissa Cull ${ }^{1}$, John P Bleasdale ${ }^{1}$, Edward N Fogden ${ }^{1}$, Mark R Anderson ${ }^{1}$ and Paul Cockwell ${ }^{3}$

${ }^{1}$ Sandwell \& West Birmingham NHS Trust, City Hospital, Birmingham, England

${ }^{2}$ Guy's and St Thomas' Hospitals, London, England

${ }^{3}$ Queen Elizabeth Hospital, Birmingham, England

Submission: July 16, 2021; Published: July 30, 2021

*Corresponding author: Bob Ryder, Sandwell \& West Birmingham NHS Trust, City Hospital, Dudley Road Birmingham B18 7QH, UK

\section{Abstract}

Aims: EndoBarrier, a $60 \mathrm{~cm}$ proximal intestinal liner, endoscopically implanted for up to one-year, reduces weight and $\mathrm{HbA1}$. As the risk of progressive chronic kidney disease (CKD) is increased by high BMI, we assessed the impact of EndoBarrier on renal function.

Methods: Between October 2014 and November 2017 we implanted EndoBarriers in 62 patients with sub-optimally controlled diabesity in our NHS service; by November 2018 all were explanted. Clinical and laboratory outcomes, including routinely performed kidney function testing by serum creatinine and MDRD eGFR, were collected in a registry

Results: In 61 patients (aged 51.4 \pm 7.2 years, 54.1\% male, 57.4\% europid, diabetes duration 12.0 (8.0-19.5) years, 57.4\% insulin-treated, BMI $41.9 \pm 7.4 \mathrm{~kg} / \mathrm{m} 2)$ with implant and explant data, weight fell by $15.9 \pm 8.5 \mathrm{~kg}$ from $122.6 \pm 27.9$ to $106.7 \pm 28.9 \mathrm{~kg}(\mathrm{p}<0.001), \mathrm{BMI}$ from $41.9 \pm 7.4$ to $36.2 \pm 7.6 \mathrm{~kg} / \mathrm{m} 2(\mathrm{p}<0.001)$ and systolic blood pressure (BP) from $138.5 \pm 15.0$ to $125.8 \pm 14.6 \mathrm{mmHg}(\mathrm{p}<0.001)$, mean $\pm \mathrm{SD}$. HbA1c fell by $23.7 \pm 21.4 \mathrm{mmol} / \mathrm{mol}$ from $80.2 \pm 22.5$ to $56.5 \pm 11.5 \mathrm{mmol} / \mathrm{mol}(\mathrm{p}<0.001)$, cholesterol from $4.7 \pm 1.4$ to $3.9 \pm 0.9 \mathrm{mmol} / \mathrm{L}(\mathrm{p}<0.001)$ and alanineaminotransferase (ALT - a marker of liver fat) from $33.2 \pm 19.8$ to $19.5 \pm 11.4 \mathrm{U} / \mathrm{L}(\mathrm{p}<0.001)$. In the 35 insulin-treated patients median (IQR) insulin dose reduced from 100 (54-140) to $40(0-70)$ units ( $\mathrm{p}<0.001)$ with 10/35 (28.6\%) discontinuing insulin. With regard to renal function, mean \pm SD serum creatinine improved by $5.5 \pm 15.4 \mu \mathrm{mol} / \mathrm{L}$ from $91.7 \pm 47.7$ to $86.2 \pm 45.7 \mu \mathrm{mol} / \mathrm{L}$ ( $\mathrm{p}=0.007)$ and estimated-Glomerular-FiltrationRate (abbreviated MDRD equation) improved by $5.8 \pm 10.7 \mathrm{ml} / \mathrm{min} / 1.73 \mathrm{~m} 2$ from $84.3 \pm 25.2$ to $90.1 \pm 26.4 \mathrm{ml} / \mathrm{min} / 1.73 \mathrm{~m} 2$ ( $\mathrm{p}<0.001$ ). Five patients had raised serum creatinine $(>133 \mu \mathrm{mol} / \mathrm{L})$ prior to Endobarrier; after implantation in four of these creatinine reduced and in two normalised. The four patients with renal impairment who sustained improvement had large weight loss (19.3-34.4 kg), the patient without improvement had only $6.6 \mathrm{~kg}$ weight loss.

Conclusion: As well as previously documented improvements in weight, HbA1c, BP, ALT and cholesterol, EndoBarrier was associated with improvements in renal function. These observational findings warrant further investigation through prospective study of the impact of such bariatric interventions on progressive CKD.

Keywords: EndoBarrier; Weight loss; Cholesterol; Endoscopic insertion; Blood pressure; Glycaemic control

Abbreviations: CKD: Chronic Kidney Disease; BP: Blood Pressure; ALT: Alanine-Aminotransferase; eGFR: Estimated Glomerular Filtration Rate

\section{Introduction}

Background and rationale: EndoBarrier ${ }^{\circ}$ (GI Dynamics, Boston, USA), also known as the duodenal-jejunal bypass liner, is a $60 \mathrm{~cm}$ long impermeable fluoropolymer sleeve which is implanted by endoscopy into the first part of the small intestine where it remains for about 1 year (Figure 1). It is held in place by a nitinol anchor, such that food passes through it without coming into contact with the small intestine, thereby interfering with the normal digestive processes that occur in this region [1]. 


\section{Current Research in Diabetes \& Obesity Journal}

The endoscopic insertion and removal of EndoBarrier are day case procedures, performed in less than an hour under general anaesthesia. This form of reversible bariatric procedure has been shown to reduce weight and improve glycaemic control in patients with diabetes and obesity [2-7].

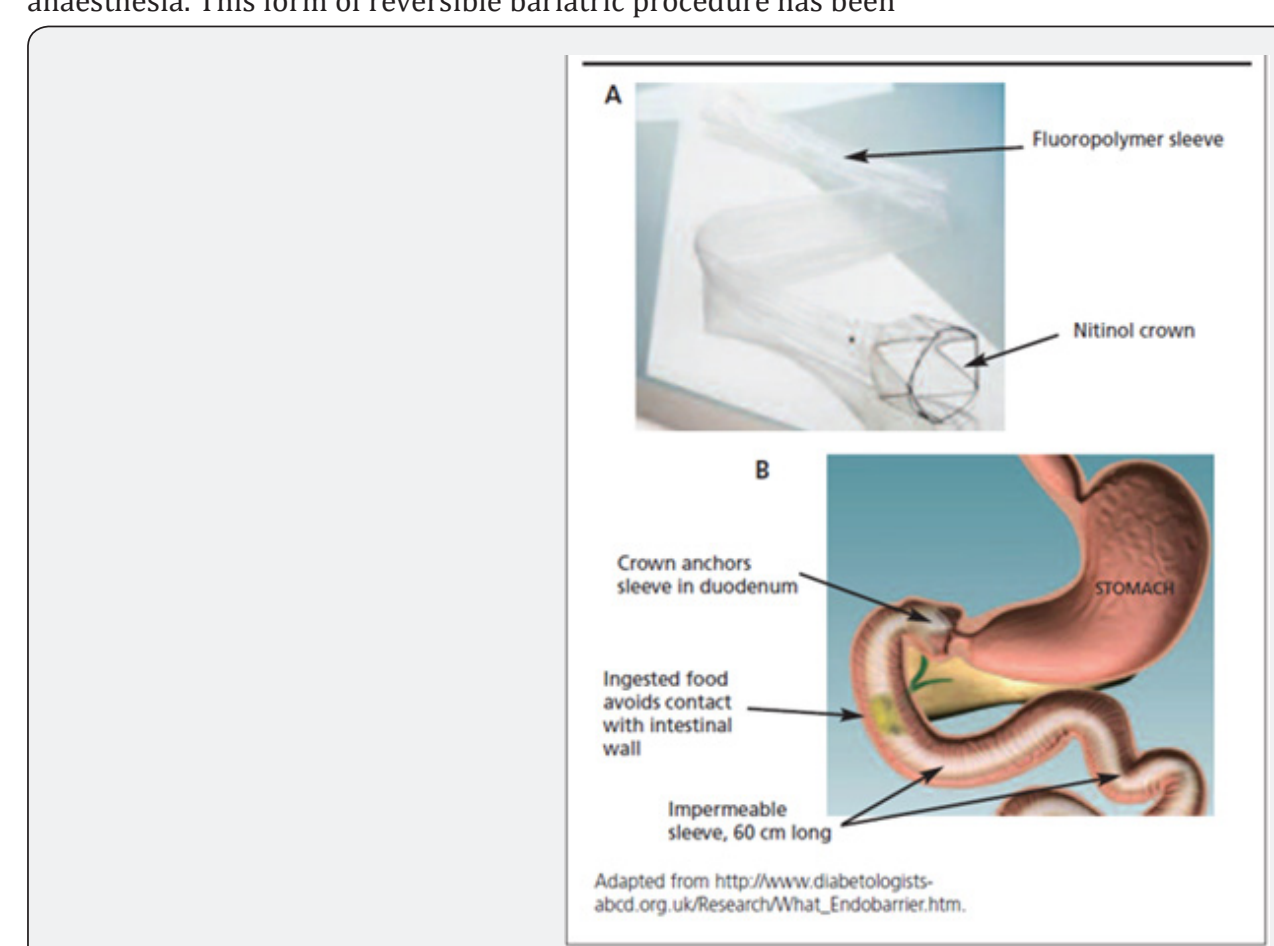

Figure 1A): The endobarrier device and (B) A diagram of the device in situ.

We have previously reported our experience from setting up the first NHS EndoBarrier service for advanced diabesity and we reported the outcomes for all 62 of the patients we treated with EndoBarrier [7]. We demonstrated that in people with obesity and poor glycaemic control and a long duration of diabetes, EndoBarrier led to a considerable improvement in weight, and microvascular risk as indicated by improvement in blood pressure and glycaemic control [7]. There was also a reduction in cardiovascular risk as assessed by the UK PDS risk engine [7]. There was a reduction in a marker of fatty liver and in those on insulin a substantial reduction in required insulin dose, including $30 \%$ discontinuing insulin [7].

As the risk of progressive chronic kidney disease is increased in individuals with high BMI [8], we assessed the impact of EndoBarrier induced weight loss on renal function in this same group of patients.

Objectives: Specifically, we aimed to assess serum creatinine and estimated glomerular filtration rate (eGFR) before EndoBarrier implantation and at explant. We aimed to assess these parameters alongside the other parameters collected at these time points, in particular weight, HbA1c and systolic blood pressure.

\section{Methods}

Study Design and Setting: We designed a comprehensive twoyear pathway, as previously described [7]. Patients were seen at the Diabetes Centre at City Hospital in Birmingham, UK, in NHS clinics specifically set up for the purpose. The Gastroenterologists responsible for EndoBarrier implantation and explantation saw the patients in a different clinic in the same setting. As previously described [7], the implantation and explantation procedures were carried out, with the support of an anaesthetist, in an endoscopy theatre suite equipped with Fluoroscopy screening. The first EndoBarrier implantation was in October 2014 and the last one in November 2017 with the last EndoBarrier explanted in November 2018 [7].

Participants: The patients had type 2 diabetes, were aged between 28 and 70 years, BMI $>30 \mathrm{~kg} / \mathrm{m}^{2}$, and must have already tried diet, lifestyle and other medications, including GLP1 receptor agonists and SGLT2 inhibitors, once these became available [7]. Thus, the only options left were; to start insulin, to increase insulin further if already on insulin, or bariatric surgery/procedure [7]. HbA1c $>58 \mathrm{mmols} / \mathrm{mol}(7.5 \%)$ at time of assessment was required unless the patient's insulin treatment to maintain a HbA1c lower than this threshold was contributing significantly to the obesity [7]. Patients with a HbA1c $>58$ mmols/ mol (7.5\%) at assessment, who had a HbA1c below this threshold immediately before the planned Endobarrier implantation, proceeded to implantation [7]. Patients taking aspirin or other antiplatelet medication that could not safely be stopped were excluded [7]. Patients were tested (stool sample) for Helicobacter pylori (H. pylori) and those who were test positive were excluded unless this was eradicated by antibiotic treatment [7]. 


\section{Current Research in Diabetes \& Obesity Journal}

Variables: We recorded baseline age, sex, ethnicity, smoking history, diabetes duration and medications. We measured at baseline and at 3 monthly intervals following EndoBarrier implantation, HbA1c, weight and BMI, serum creatinine, eGFR, systolic blood pressure, cholesterol, HDL cholesterol, cardiovascular risk as assessed by the UKPDS risk engine v2 [9], alanine aminotransferase (a marker of fatty liver disease [7]), diabetes medications - in particular insulin dose if applicable [7]. Side effects were recorded, in particular gastro-intestinal side effects and any serious adverse events leading to early removal of the EndoBarrier [7]. Patient satisfaction was assessed using the NHS friends and family test [10]. Weight and height were measured on standard out-patient equipment. Biochemistry parameters were measured in the pathology department at City Hospital.

Sources of bias: As we were auditing routine practice, we could not interfere with standard care which might have impacted on the results, for example medications for hypertension that may have been added in during the year of treatment that may have had an impact and medications for other conditions such as steroids for inflammatory conditions or medications for mental health.

Study size: This was an overservational study to report early outcomes in all patients we treated with EndoBarrier [7]. After implantation into 62 such patients, the CE mark for EndoBarrier was suspended (November 2017 [11]) and we present here the data on all 62 patients up until explantation of the last one in November 2018.

Statistical methods: The impact of EndoBarrier on the parameters measured at follow-up was assessed by comparing the parameter in the last value measured prior to explantation with the baseline value using a paired student t-test. As all patients had to attend in order to have EndoBarrier explantation, explantation data was obtained on all patients except for one whose explantation occurred within 3 weeks due to noncompliance with the safety advice [7].

Table 2: The impact of EndoBarrier treatment on mean \pm SD weight, HbA1c and CVD risk factors and alanine-aminotransferase (ALT - a liver fat marker) in 61 patients. There were highly significant falls in all parameters involved in CVD risk assessment other than HDL cholesterol which remained unchanged.

\begin{tabular}{|c|c|c|c|c|}
\hline Parameter & Baseline & Atexplant & Difference & P-value \\
\hline Weight (kg) & $122.6 \pm 27.9$ & $106.7 \pm 28.9$ & $-15.9 \pm 8.5$ & $<0.001$ \\
\hline BMI $\left(\mathrm{kg} / \mathrm{m}^{2}\right)$ & $41.9 \pm 7.4$ & $36.2 \pm 7.6$ & $-5.7 \pm 3.2$ & $<0.001$ \\
\hline HbAIc (mmol/mol) & $80.2 \pm 22.5$ & $56.5 \pm 11.5$ & $23.7 \pm 21.4$ & $<0.001$ \\
\hline HbA1c (\%) & $9.5 \pm 2.1$ & $7.3 \pm 1.1$ & $2.2 \pm 2.0$ & $<0.001$ \\
\hline Systolic blood pressure (mmHg) & $138.5 \pm 15.0$ & $125.8 \pm 14.6$ & $12.7 \pm 16.2$ & $<0.001$ \\
\hline Cholesterol (mmol/L) & $4.71 \pm 1.35$ & $3.86 \pm 0.86$ & $0.86 \pm 1.13$ & $<0.001$ \\
\hline HDL (mmol/L) & $1.13 \pm 0.27$ & $1.10 \pm 0.30$ & $0.04 \pm 0.22$ & 0.135 \\
\hline $\operatorname{ALT}(\mathrm{U} / \mathrm{I})$ & $33.2 \pm 19.8$ & $19.5 \pm 11.4$ & $-13.7 \pm 20.1$ & $<0.001$ \\
\hline Insulin daily dose (Median (IQR) $(\mathrm{n}=35)^{*}$ & $100(60-135)$ & $40(0-70)$ & -60 & $<0.001$ \\
\hline
\end{tabular}




\section{Current Research in Diabetes \& Obesity Journal}

Table 3 shows the impact of EndoBarrier treatment on renal function as measured by serum creatinine and eGFR. Serum creatinine fell by a mean of $5.5 \pm 15.4 \mu \mathrm{mol} / \mathrm{L}$ from $91.7 \pm 47.7$ to $86.2 \pm 45.7 \mu \mathrm{mol} / \mathrm{L}(\mathrm{P}=0.007)$. eGFR increased by $5.8 \pm 10.7 \mathrm{ml} /$ $\mathrm{min} / 1.73 \mathrm{~m}^{2}$ from $84.3 \pm 25.2$ to $90.1 \pm 26.4 \mathrm{ml} / \mathrm{min}$ per $1.73 \mathrm{~m}^{2}$ $(\mathrm{P}<0.001)$.

Five patients had a raised serum creatinine $(>133 \mu \mathrm{mol} / \mathrm{L})$

Table 3: EndoBarrier had a significant impact on renal function. prior to EndoBarrier treatment. During EndoBarrier treatment in 4 of these patients the creatinine reduced, and in 2 the creatinine normalised. Table 4 shows the before and after creatinine data for these 5 patients with the weight data given alongside. It is noteworthy that the 4 patients with renal impairment who sustained an improvement in kidney function had a large weight loss $(19.3-33.4 \mathrm{~kg})$ whereas in the patient without improvement in renal function the weight loss was only $6.6 \mathrm{~kg}$.

\begin{tabular}{|c|c|c|c|c|}
\hline Parameter & Baseline & At Explant & Difference & P-value \\
\hline Serum Ceratinine $(\mathrm{umol} / \mathrm{L})$ & $91.7 \pm 47.7$ & $86.2 \pm 45.7$ & $5.5 \pm 15.4$ & 0.007 \\
\hline eGFR $\left(\mathrm{ml} / \mathrm{min} / 1.73 \mathrm{~m}^{2}\right)$ & $84.3 \pm 25.2$ & $90.1 \pm 26.4$ & $5.8 \pm 10.7$ & $<0.001$ \\
\hline
\end{tabular}

Table 4: Five patients had a raised serum creatinine ( $>133 \mu \mathrm{mol} / \mathrm{L})$ prior to EndoBarrier; after implantation in four of these patients the creatinine reduced and in two creatinine normalized.

\begin{tabular}{|l|c|c|c|c|c|c|}
\hline Patient & $\begin{array}{c}\text { Creatinine at Baseline } \\
\text { (umol/L) }\end{array}$ & $\begin{array}{c}\text { Creatinine at Explant } \\
\text { (umol/L) }\end{array}$ & $\begin{array}{c}\text { Weight at Baseline } \\
\text { (Kg) }\end{array}$ & $\begin{array}{c}\text { Weight at Explant } \\
\text { (Kg) }\end{array}$ & $\begin{array}{c}\text { Weight Loss } \\
\text { (Kg) }\end{array}$ & Comment \\
\hline Patient 1 & 348 & 281 & 128.2 & 108.9 & 124.6 & $\begin{array}{c}\text { Big weight loss creati- } \\
\text { nine improved }\end{array}$ \\
\hline Patient 2 & 284 & 329 & 131.2 & 98.8 & $\begin{array}{c}\text { Small weight loss cre- } \\
\text { atinine deteriorated }\end{array}$ \\
\hline Patient 3 & 166 & 152 & 122.4 & $\begin{array}{c}\text { Big weight loss creati- } \\
\text { nine improved }\end{array}$ \\
\hline Patient 4 & 153 & 106 & 92.4 & 73 & 19.4 & $\begin{array}{c}\text { Big weight loss creati- } \\
\text { nine normalized }\end{array}$ \\
\hline Patient 5 & 153 & 133 & 145.4 & 111 & 34.4 & $\begin{array}{c}\text { Big weight loss creati- } \\
\text { nine normalized }\end{array}$ \\
\hline
\end{tabular}

Early removal: As previously documented 10 of the 62 patients implanted with EndoBarrier (16\%) required early removal, 4 for gastro-intestinal haemorrhage, 2 for liver abscess, 1 for another abdominal abscess and 3 for gastro-intestinal symptoms [7]. In several cases there were issues with compliance which led to early removal and we have previously reported the detail of this [7]. All made a full recovery following device removal and most derived benefit despite the early removal [7].

Patient satisfaction: As previously reported [7], patients reported considerable increase in fitness and wellbeing and in the NHS friends and family test (10) in response to the question "how likely would you be to recommend this treatment to friends and family?", $84 \%$ replied "extremely likely" with a further $12 \%$ reporting "likely".

\section{Discussion}

Key results: As previously documented, EndoBarrier resulted in substantial weight loss (mean $15.9 \mathrm{~kg}$ ), improvement in glycaemic control (mean 23.7 mmols/L from 82.2 - 56.5 mmols/L), significant reduction in a marker of fatty liver, and improvement in cardiovascular risk factors, and for those on insulin a substantial reduction in insulin dose with $28.6 \%$ insulin-treated patients discontinuing insulin [7]. Patients reported considerable increase in fitness and wellbeing and all patients with early removal because of serious adverse events made a full recovery and most derived significant benefit despite the early removal [7]. Alongside these previously documented improvements EndoBarrier was also associated with improvement in renal function (mean serum creatinine fall by $5.5 \mu \mathrm{mol} / \mathrm{L}$ from $91.7 \mu \mathrm{mol} / \mathrm{L}$ to $86.2 \mu \mathrm{mol} / \mathrm{L}$ and mean eGFR increasing by $5.8 \mathrm{ml} / \mathrm{min}$ per $1.73 \mathrm{~m}^{2}$ from 84.3 to $90.1 \mathrm{ml} / \mathrm{min}$ per $1.73 \mathrm{~m}^{2}$ ).

Limitations: The main limitation of this study is lack of a control group. The patients had previously tried to lose weight of many years and all had tried medications known to help with weight loss, such as GLP-1 receptor agonists and SGLT2 inhibitors once they became available. Nevertheless, we cannot be sure from this cohort study what contribution there might have been from the placebo effect. In the current pivotal study with EndoBarrier of the United States Food and Drug Administration (FDA) [12], there is a sham control group who will receive an endoscopic examination without insertion of an EndoBarrier in a doubleblind randomised fashion to address this issue. Nevertheless, it seems unlikely that a placebo affect would achieve anything like the degree of improvement in weight and metabolic outcomes achieved in the current cohort study. Regarding renal function testing, measured GFR may have given a more accurate assessment of the impact of Endobarrier on kidney function. However, the MDRD eGFR has good accuracy for estimation of kidney function 
and mGFR is not deliverable in a routine service evaluation.

Interpretation: As reported previously [7], all the patients with early removal because of serious adverse events made a full recovery and most derived considerable benefit despite the setback. Indeed, the mean $\mathrm{HbA1c}$ fall of $24.8 \mathrm{mmol} / \mathrm{mol}$ and weight loss of $13.6 \mathrm{~kg}$ from $114.9 \pm 22.8$ to $101.3 \pm 22.8 \mathrm{~kg}(\mathrm{p}<0.001)$ are improvements experienced by the early removal group that were not greatly different from those of the full cohort [7]. The improvement in renal function associated with EndoBarrier induced weight loss is compatible with improvements in renal function associated with weight loss induced by bariatric surgery $[13,14]$ and our results are in keeping with this additional benefit to patients over and above those previously reported for EndoBarrier. The potential impact of EndoBarrier on kidney function should be a focus for further evaluation. The development of renal impairment is associated with an over 5-fold increase in 10-year mortality risk in patients with Type 2 DM [15], and obesity is a major independent risk factor for accelerated progression of CKD [16].

EndoBarrier treatment requires only a relatively simple endoscopy procedure and it is noteworthy that endoscopy units and skilled endoscopists are ubiquitous throughout the NHS. In the context of the diabesity pandemic [17], there is a need for simpler treatments that are less invasive than bariatric surgery for the many patients with obesity and poorly controlled diabetes despite lifestyle and pharmaceutical interventions. Such patients are at very high cardiovascular risk [18-20] and our data suggests that EndoBarrier may reduce this risk [7]. These patients are also at high risk of the microvascular complications and it is well established that improving HbA1c and blood pressure, as EndoBarrier does in these patients, improves microvascular outcomes [21-24]. The benefits to the patients are particularly obvious when individual anecdotes are considered [25] (the patients on pages 12 and 13 in reference 25 are examples of patients who gained renal benefit). Follow up of our patients demonstrates maintenance of significant improvement one year after removal in $78 \%$ of cases for whom data were available [26]. Therefore, EndoBarrier deserves further investigation as potential treatment for wider use in uncontrolled diabesity, especially bearing in mind the cardiovascular and microvascular risk to these patients if they are not given additional treatment. The potential impact on renal function may also contribute to the potential for improved clinical outcomes.

Generalisability: Endoscopy units are ubiquitous throughout the NHS, as are skilled endoscopists. Patients with uncontrolled diabesity are also ubiquitous throughout the NHS and therefore it would be relatively easy to make EndoBarrier widely available. The lessons we have learned with regard to measures to minimise early removal for serious adverse events would also be useful to future services.

\section{Acknowledgement}

The success of the project was down to a team effort with many people involved. We would like thank in particular all of the endoscopy, anaesthetic and diabetes staff involved in the care of these patients, and Dominic Jackson from Elemental Healthcare Limited who supported with his long-standing expertise with EndoBarrier. Special thanks to Melanie Wyres who was the administrative rock at the core of the project. Finally, thanks to our chief executive, Toby Lewis, for his crucial support in getting this innovative new service established in our busy hospital despite so many other priorities, and for facilitating negotiations with the local CCG.

\section{Conflict of Interest}

Dr Bob Ryder has received speaker fees, and/or consultancy fees and/or educational sponsorships from AstraZeneca, BioQuest, GI Dynamics, Janssen and Novo Nordisk. All other coauthors have nothing to declare.

\section{References}

1. http://gidynamics.com/wp-content/uploads/2017/09/50-1000552-Rev-N-IFU-EB-GI-Liner-with-Delivery-System.pdf.

2. de Jonge C, Rensen SS, Verdam FJ, Royce P Vincent, Steve R Bloom, et al. (2013) Endoscopic Duodenal-Jejunal Bypass Liner Rapidly Improves Type 2 Diabetes. Obes Surg 23(9): 1354-1360.

3. Betzel B, Homan J, Aarts EO, Ignace M C Janssen, Hans de Boer, et al. (2017) Weight reduction and improvement in diabetes by the duodenal-jejunal bypass liner: a 198 patient cohort study. Surg Endosc 31: 2881-2891.

4. Petra Kaválková, Miloš Mráz, Pavel Trachta, Jana Kloučková, Anna Cinkajzlová, et al. (2016) Endocrine effects of duodenal-jejunal exclusion in obese patients with type 2 diabetes mellitus. J Endocrinol 231(1): 11-22.

5. Koehestanie P, Dogan K, Berends F, Ignace Janssen, Peter Wahab, et al. (2014) Duodenal-jejunal bypass liner implantation provokes rapid weight loss and improved glycemic control, accompanied by elevated fasting ghrelin levels. Endosc Int Open 2(1): E21-E27.

6. Jirapinyo, Haas AV, Thompson CC (2018) Effect of the Duodenal-Jejunal Bypass Liner on Glycemic Control in Patients with Type 2 Diabetes with Obesity: A Meta-analysis with Secondary Analysis on Weight Loss and Hormonal Changes. Diabetes Care 41(5): 1106-1115.

7. Ryder REJ, Irwin SP, Burbridge W, et al. (2019) The United Kingdom's first NHS Endobarrier service for advanced diabesity: 1-year outcomes for all 62 treated patients. Br J Diabetes 19: 110-117.

8. Chang AR, Grams ME, Ballew SH (2019) Adiposity and risk of decline in glomerular filtration rate: meta-analysis of individual participant data in a global consortium. BMJ 364: k5301.

9. https://www.dtu.ox.ac.uk/riskengine/.

10. https://www.england.nhs.uk/fft/.

11. https://gidynamics.com/2017/11/12/gi-dynamics-receives-cecertificate-conformity-withdrawal-notice-endobarrier/.

12. https://gidynamics.com/2018/08/12/gi-dynamics-announces-fdaapproval-endobarrier-pivotal-trial/. 


\section{Current Research in Diabetes \& Obesity Journal}

13. Chao AT, Fang SC, Lam BCC (2018) Effect of bariatric surgery on diabetic nephropathy in obese type 2 diabetes patients in a retrospective 2-year study: A local pilot. Diab Vasc Dis Res 15(2): 139-144.

14. Kun L, Jianan Z, Zhibin Ye, Jianzhong Di, Xiaodong Han, et al. (2016) Effects of Bariatric Surgery on Renal Function in Obese Patients: A Systematic Review and Meta Analysis. PLoS One 11(10): e0163907.

15. Afkarian M, Sachs MC, Kestenbaum B, Irl B Hirsch, Katherine R Tuttle, et al. (2013) Kidney disease and increased mortality risk in type 2 diabetes. J Am Soc Nephrol 24(2): 302-308.

16. Chang AR, Grams ME, Ballew SH (2019) Adiposity and risk of decline in glomerular filtration rate: meta-analysis of individual participant data in a global consortium. BMJ 364: k5301.

17. https://www.diabetesatlas.org/en/sections/worldwide-toll-ofdiabetes.html .

18. Fisher M, Shaw KM (2001) Diabetes - a state of premature cardiovascular death. Pract Diabetes Int 18: 183-184.

19. Goodkin G (1975) Mortality factors in diabetes. A 20-year mortality study. Journal of Occupational Medicine 17(11): 716-721.
20. Donnelly R, Emslie-Smith AM, Gardner ID (2000) Vascular complications of diabetes. British Medical Journal 320: 1062-1066.

21. https://www.dtu.ox.ac.uk/ukpds/.

22. UK Prospective Diabetes Study Group (1998) Tight blood pressure control and risk of macrovascular and microvascular complications in type 2 diabetes: UKPDS 317: 703-713.

23. UK Prospective Diabetes Study Group (1998) Efficacy of atenolol and captopril in reducing risk of macrovascular and microvascular complications in type 2 diabetes: UKPDS 39, BMJ 317: 713720.

24. UK Prospective Diabetes Study (UKPDS) Group (1998) Intensive blood-glucose control with sulphonylureas or insulin compared with conventional treatment and risk of complications in patients with type 2 diabetes (UKPDS 33). Lancet 352(9131): 837-853.

25. http://www.diabetologists-abcd.org.uk/Endobarrier/Birmingham Endobarrier_patients.pdf.

26. Ryder REJ, Yadagiri M, Burbridge W (2021) The United Kingdom's first NHS EndoBarrier service for long-standing poorly controlled type 2 diabetes and obesity: outcomes one year after EndoBarrier removal. Br J Diabetes 21: 76-83

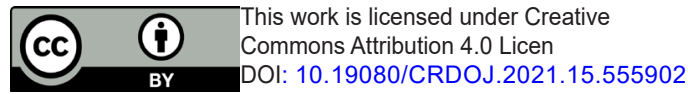

Your next submission with Juniper Publishers
will reach you the below assets
- Quality Editorial service
- Swift Peer Review
- Reprints availability
- E-prints Service
- Manuscript Podcast for convenient understanding
- Global attainment for your research
- Manuscript accessibility in different formats
( Pdf, E-pub, Full Text, Audio)
- Unceasing customer service
Track the below URL for one-step submission
https://juniperpublishers.com/online-submission.php

